\title{
Poor compliance to inhaler therapy in bronchial asthma patients -a prospective study in general population
}

\author{
Gajanan Gaude*, Jyothi Hattiholi, Alisha Chaudhury \\ Department of Pulmonary Medicine, KLE University's Jawaharlal Nehru Medical College, Belgaum, Karnataka, INDIA
}

\section{Email address:}

gsgaude922@gmail.com (G. Gaude)

\section{To cite this article:}

Gajanan Gaude, Jyothi Hattiholi, Alisha Chaudhury. Poor Compliance to Inhaler Therapy in Bronchial Asthma Patients -A Prospective Study in General Population. Science Journal of Clinical Medicine Vol. 3, No. 1, 2014, pp. 4-9. doi: 10.11648/j.sjcm.20140301.12

\begin{abstract}
Background: Considering the prevalence and associated burden of disease due to bronchial asthma, it is mandatory to obtain an optimal control of the disease and to improve outcomes for these patients. Asthma control and treatment compliance are widely investigated issues around the world. But it has been observed that there is very poor adherence to the inhalational therapy which leads to the sub-optimal control of the disease. Objectives of the study: To investigate the adherence for anti-asthma inhalational medications in adults with bronchial asthma. Methodology: A prospective study was done in a total of 400 bronchial asthma patients over a period of 2 years. Once included in the study, the patients were followed up for a total of 12 weeks for calculation of non-adherence to the aerosol therapy. Results: A total of 400 patients of bronchial asthma who were started on inhalational therapy were included in the study. At the end of 12 weeks, it was observed that, only 154 patients (38.5\%) had regular compliance and 246 patients $(61.5 \%)$ were noncompliant to aerosol therapy as prescribed for bronchial asthma. Factors that were associated with poor compliance were: lower educational level status, poor socio-economic status, cumbersome regimens, dislike of medication and distant pharmacies. Non-Drug factors that reduced the compliance were: fears about side effects, anger about condition or its treatment, forgetfulness or complacency and patient's ill attitudes toward health. Conclusion: Noncompliance in asthma management is a fact of life and no single compliance-improving strategy probably will be as effective as a good physician-patient relationship. Optimal self-management allowing for optimization of asthma control by adjustment of medications may be conducted by either self-adjustment with the aid of a written action plan or by regular medical review.
\end{abstract}

Keywords: Bronchial Asthma, Compliance, Non-Adherence, Health Education

\section{Introduction}

Asthma is a major public health problem affecting a large medication; one such report described patients with hyper number of individuals of all ages. The severity of asthma varies within and between individuals. The economic burden is well documented in industrialized countries. Poor asthma control is responsible for a large proportion of medication and its prescribed use, and both direct and indirect costs would decrease if control were improved. Poor compliance with prescribed therapy leads to increased morbidity and mortality. Estimates indicate that, India has $20-28$ millions asthmatics and the prevalence amongst children ( 5 to 11 years) is $10 \%$ to $15 \%$. Being a chronic medical condition, management of bronchial asthma requires continuous medical care. Modern management of bronchial asthma requires prolonged medications. Medications for asthma reverse and prevent symptoms and airflow limitations. A key issue in proper management of bronchial asthma is adherence to treatment. Poor compliance to prescribed therapy increases morbidity and mortality and it is increasingly being documented that long term compliance or adherence to prescribed therapy is hard to attain ${ }^{1}$. Studies have reported that $50 \%$ of patients with a chronic disease do not use their medication at all or do not use it as prescribed ${ }^{2}$. A key reason for poor compliance is that patients with a chronic disease do not have a satisfactory understanding of their condition. The economic burden of bronchial asthma to the society is well documented in industrialized countries ${ }^{3}$, and is a great burden to the Health services. Poor asthma control is responsible for a large proportion of the total cost of the disease, for the patient as well as to the society, and thus consequently, in improving compliance and thereby control of the disease, would decrease both direct and indirect cost to the patient. 
The present study was undertaken to investigate the factors that influence patient's compliance with prescribed inhalational medications for bronchial asthma in Indian population.

\section{Materials and Methods}

The present study was a prospective study done at Dr. Prabhakar Kore Hospital \& MRC, Belgaum over a period of 2 years from June 2010 to May 2012. Children above 15 years of age and adults with the diagnosis of bronchial asthma as per GINA Guidelines ${ }^{4}$ were included in the study. Patients with acute severe asthma, COPD, and cardiac asthma were excluded. All patients were interviewed using a standard interview schedule and requested to maintain a diary regarding the dosing of aerosol therapy. A combined questionnaire - including demographic data, educational level, self-determined socioeconomic status, smoking history, asthma control and treatment-compliance scores was filled out by each patient with the assistance of the medical staff. Each patient was interviewed and questionnaires were completed during a routine visit. No therapeutic interventions were performed until completion of the study protocol. Apart from a detailed history, physical examination, pulmonary function test and peak expiratory flow rate were measured during the first visit. All the patients were treated according to GINA guidelines under the supervision of chest physicians. Regarding the choice of the regimen and the drugs to be used for control of bronchial asthma, the choice was left to the treating chest physician. All patients were followed up every 15 days for 12 weeks. At the end of 12 weeks, compliance to treatment was calculated after studying the patient diary noting and frequency of the hospital visits. Control of the disease was assessed by pulmonary function testing and peak expiratory flow rate measurements. Compliant day was defined as one in which the prescribed number of puffs (MDI) or dry powder inhalation capsules were taken each day. Patient was said to be compliant if he/she had taken more than $80 \%$ of the prescribed medicines during the study period.

The economic status was classified as per modified B. G. Prasad classification ${ }^{5}$. Income levels initially proposed by Prasad can be converted into currently applicable levels by multiplying with a factor of $0.0493 \times$ Prevailing level of All India Consumer Price Index (AICPI). The average AICPI during the study period was 26. Hence, the per capita income in class I was Rs.2,600 per head per month, in class II it was Rs. 1,300 to 2,340 per head per month, in class III it was between Rs. 780 to 1,274 per head per month, in class IV it was Rs. 390 to 754 per head per month and class $\mathrm{V}$ less than Rs. 390 per head per month.

\subsection{Statistical Analysis}

Data are expressed as the mean (SD). Comparison of parameters between two groups was done by Student's $t$ test. Comparisons among three groups were done by one- way ANOVA with Bonferroni's multiple comparison tests. Differences in frequency between compliance and noncompliance patients were assessed by the chi-square test. A $\mathrm{p}$ value of less than 0.05 was considered significant.

\section{Results}

A total of 400 patients were studied during the period. The majority of the patients $(39 \%)$ were in the age group of 21-40 years. A total of $17 \%$ were adolescents, while children and those more than 70 years were $5 \%$ and $6 \%$ respectively. The male: female ratio was 3:2. Majority of patients $290(58 \%)$ had either primary or secondary education and $10 \%$ were illiterate. The majority of the patients belonged to middle socio-economic status (Table $1)$.

Table 1. Baseline characteristics of the patients

\begin{tabular}{|c|c|c|}
\hline Variables & No. ( \% ) & p value \\
\hline \multicolumn{3}{|l|}{ Gender: } \\
\hline Males & $245(61)$ & \multirow{2}{*}{0.05} \\
\hline Females & $155(39)$ & \\
\hline \multicolumn{3}{|l|}{ Age (years): } \\
\hline Mean & $36.2 \pm 17.4$ & \\
\hline Median & 35 & \\
\hline \multicolumn{3}{|l|}{ Duration of asthma disease: } \\
\hline $1-5$ years & $255(64)$ & \\
\hline $6-10$ years & $85(21)$ & \\
\hline$>10$ years & $60(15)$ & \\
\hline \multicolumn{3}{|l|}{ Educational status: } \\
\hline Illiterate & $40(10)$ & \multirow{5}{*}{0.01} \\
\hline Primary & $110(28)$ & \\
\hline Secondary & $130(32)$ & \\
\hline Graduate & $110(28)$ & \\
\hline Postgraduate & $10(2)$ & \\
\hline \multicolumn{3}{|l|}{ Economic status: } \\
\hline Lower & $145(36)$ & \multirow{3}{*}{0.05} \\
\hline Middle & $180(45)$ & \\
\hline Upper & $75(19)$ & \\
\hline Smoking history & $164(41)$ & 0.01 \\
\hline Current as needed medicines & $244(56)$ & 0.01 \\
\hline $\begin{array}{l}\text { Emergency visits for respiratory } \\
\text { complaints over last } 12 \text { months }\end{array}$ & $264(66)$ & 0.01 \\
\hline
\end{tabular}

Nearly one-third of the patients (154 patients, 38.5\%) was regular to aerosol therapy and did not miss a single dose and the remaining 61.5\% were non-compliant. Among male patients, regular compliance was observed in 111 patients, while 52 female patients were regular to the therapy. A higher number of male patients missed more than 20 doses over duration of 12 weeks $(56.6 \%)$ as compared to female patients $(43.3 \%)$. While the association between male and female was not significant, education status was significant and there was moderate correlation between educational status and compliance to the therapy. Socio-economic status of the patient was significant risk factor associated with the non-compliance to the therapy. More than two-third of patients $(80 \%)$ were using dry 
powder inhalers (DPI), and 20\% were using metered dose inhalers (MDI) and remaining 18 patients $(6 \%)$ used combination of the drugs (Table 2).

Table 2. Factors affecting compliance for aerosol therapy

\begin{tabular}{llll}
\hline Variables & $\begin{array}{l}\text { Non-compliant, } \\
(\mathbf{2 4 6 )}\end{array}$ & $\begin{array}{l}\text { Compliant } \\
(\mathbf{1 5 4 )}\end{array}$ & p value \\
\hline Age & 38.0 & 35.4 & 0.12 \\
Mean SD & 17.0 & 11.5 & \\
$\begin{array}{l}\text { Duration asthma } \\
\text { (yrs) }\end{array}$ & & \\
1 -5 years & 141 & 114 & \\
$5-10$ years & 65 & 20 & 0.005 \\
$>10$ years & 40 & 20 & \\
$\begin{array}{l}\text { Side effects } \\
\text { No side effects }\end{array}$ & 215 & & \\
$\begin{array}{l}\text { Side effects present } \\
\text { Drugs compliance }\end{array}$ & 31 & 137 & 0.05 \\
$\begin{array}{l}\text { DPI } \\
\text { MDI }\end{array}$ & 203 & 17 & \\
Low socio-economic & 99 & 108 & 0.01 \\
status & 43 & 46 & \\
\hline
\end{tabular}

(SD -Standard Deviation)

Non drug factors were the key reasons for non-adherent to the aerosol therapy (Table 3). The major non-drug factors associated with poor compliance were: fears about side effects to the medications (18\%), higher cost of the therapy $(10 \%)$, feeling of well being on therapy $(8 \%)$ and negligence on the part of the patients $(7 \%)$. Other reasons included forgetfulness or complacency and attitudes toward ill health, anger about condition, etc. Drug related reasons for non-compliance included difficulties with inhaler devices, awkward regimes (e.g., four times daily or multiple drugs), dislike of medications and distant pharmacies.

Table 3. Causes for Non-adherence for asthma therapy $(N=246)$

\begin{tabular}{|c|c|c|c|}
\hline \multicolumn{2}{|l|}{ Non-drug related Factors } & \multicolumn{2}{|c|}{ Drug related Factors } \\
\hline Factors & No $(\%)$ & Factors & No $(\%)$ \\
\hline Fear about side effects & $45(18)$ & Cost of therapy & $30(12)$ \\
\hline Feeling of well being & $32(13)$ & $\begin{array}{l}\text { Difficulties with } \\
\text { inhaler devices }\end{array}$ & $30(12)$ \\
\hline $\begin{array}{l}\text { Negligence on the part of } \\
\text { patients }\end{array}$ & $30(12)$ & $\begin{array}{l}\text { Awkward } \\
\text { regimens }\end{array}$ & $15(6)$ \\
\hline Forgetfulness/complacency & $25(10)$ & $\begin{array}{l}\text { Dislike for } \\
\text { medications }\end{array}$ & $15(6)$ \\
\hline $\begin{array}{l}\text { Ill attitude towards chronic } \\
\text { health condition }\end{array}$ & $20(8)$ & $\begin{array}{l}\text { Distant } \\
\text { pharmacies }\end{array}$ & $12(5)$ \\
\hline Anger about condition & $15(6)$ & & \\
\hline
\end{tabular}

*Many patients had more than one reason for non-compliance.

Table 4 shows the various risk factors associated with the non-adherence to the inhalational therapy in bronchial asthma. It was observed that if the diagnosis of asthma is explained properly to the patients or the parents of the children, the adherence rate is higher. Similarly, if the health care worker listens to the patient and takes their concerns and apprehensions about the disease and gives proper explanations, then this helps in improving the noncompliance in asthma.

Table 4. Independent variables split by taking medication as prescribed or not in both the groups

\begin{tabular}{|c|c|c|c|}
\hline Variables & $\begin{array}{l}\text { Non-adherent patients } \\
\qquad(N=246)\end{array}$ & $\begin{array}{l}\text { Adherent patients } \\
\qquad(N=154)\end{array}$ & p value \\
\hline Age, Mean & 38.0 & 35.4 & 0.12 \\
\hline Female gender & 95 & 60 & 0.45 \\
\hline Acute care in the last 2 years & 46 & 43 & 0.50 \\
\hline Check-up visits at health care centre & 67 & 78 & 0.21 \\
\hline Inhalation technique checked in past 12 months & 76 & 112 & 0.45 \\
\hline Informed about diagnosis & 56 & 98 & 0.03 \\
\hline Length of time with airway problems, years, mean & 12 & 13 & 0.54 \\
\hline Problems or side effects from medication & 31 & 17 & 0.30 \\
\hline Good knowledge about medications & 66 & 71 & 0.22 \\
\hline Worry that medication will affect the patient in the future & 45 & 79 & 0.45 \\
\hline That the staff listen and take the patients views about asthma into account & 34 & 65 & 0.05 \\
\hline That the diseases is actively followed up & 43 & 23 & 0.35 \\
\hline That a health care worker is responsible for the patient and his/her asthma & 29 & 42 & 0.22 \\
\hline That the patient received information and education about the disease & 39 & 97 & 0.02 \\
\hline Self reported medications & 74 & 82 & 0.51 \\
\hline
\end{tabular}

\section{Discussion}

Bronchial asthma, a chronic lung disease that affects people of all ages, races, and ethnic groups, is a growing concern throughout the world. As a result, there has been a considerable interest in a number of areas. There is a need for educating the patient about asthma disease and medications used like DPI/ MDI to be taken on regular basis as prescribed. In the study ${ }^{6}$ conducted in Trinidad regarding the understanding and use of inhaler medication by asthmatics, it was observed that educating patients, with a focus on children and the elderly, inhaler techniques and reinforcing understanding of asthma medications could 
improve asthma management to a great extent.

Noncompliance to treatment programs is common in patients with asthma and other chronic conditions. Noncompliance is more common than usually suspected. Rates vary from $20 \%$ to $80 \%{ }^{7}$. True rates of noncompliance are hard to come by because patients do not accurately report and physicians often do not inquire critically. The rule-of-thumb in chronic nonlethal disease (i.e., asthma, hypertension, etc) is that $1 / 3$ of patients are compliant, $1 / 3$ are somewhat compliant, and $1 / 3$ are noncompliant. This is important because compliant patients are significantly less likely to experience exacerbations than less compliant patients $^{8}$. A real problem is that although there is much known about why so many patients do not take their medicine, there is less solid information on how to actually improve compliance. Methods to improve compliance must be validated with objective data and outcome measurements before they can be recommended with confidence 9 . A word about compliance versus adherence, for mixed reasons (political correctness, fashion, or a drift toward fuzzy language?), adherence seems to have become the preferred word. They imply about the same thing but compliance and noncompliance over adherence and nonadherence should be because they are stronger words and it means that the treatment program has been prescribed and that the patient has not followed it for whatever reason or reasons ${ }^{10}$.

The present study was conducted to know compliance with inhalational therapy in bronchial asthma patients and reasons for non-compliance. An effort was also made to improve the patient compliance via the patient education programme. In the present study a total of 246 patients $(61.5 \%)$ were observed to be non-compliant to the asthma therapy. Non-compliance rates were more in male patients as compared to female patients. Rhodes et $\mathrm{al}^{11}$ observed higher prevalence of asthma in female patients as compared to males. Females with current asthma, reported adult onset of asthma more often, and males reported childhood onset of symptoms more often. Sex differences were identified for the eight asthma-control characteristics. Females presented higher asthma risk and poorer asthma profiles than male patients. Gibson et $\mathrm{al}^{12}$ conducted a study to study the compliance with inhaled asthma medications in pre-school children. In pre-school children the parents supervise and are responsible for drug administration. In this study it was observed that parental supervision would result in good compliance. It was concluded that compliance with inhaled prophylactic therapy is poor in pre-school children with asthma whose medication is administrated under parental supervision. Lewis and Lewis $^{13}$ investigated the consequences of empowering children to care for themselves.

Noncompliance depends on many factors and they are difficult to sort out ${ }^{14}$. Beliefs, perceptions, and experience constitute some of the variables associated with compliant medication taking behavior ${ }^{9}$. It had been suggested that race, crime, age, and other environmental factors are associated with compliance and noncompliance but these are speculative ${ }^{15}$. Lindberg et $\mathrm{al}^{16}$ studied various factors affecting the compliance in asthma patients and have identified five important factors regarding self-reported compliance with prescribed medications in patients with asthma: age, gender, length of time with airway problems, whether the staff listen and take into account the patient's views concerning his/her asthma, and whether the patient has received information and education concerning asthma.

\subsection{Educational Status}

There were 20 patients with higher education (post graduation) and all the patients had regular compliance with the therapy. Patients having graduation degree (140 patients) also had better compliance (78\%) with the medications. Patients having secondary education had a default rate of $60 \%$, patients having primary education had a high default rate of $71.4 \%$ while illiterate patients had a default rate of $100 \%$. They also missed more number of doses of the medications. Educational status thus is a significant factor for the non-compliance to the therapy for asthma medications.

Valid educational programme for asthmatics can improve the knowledge of the disease and to understand how they look after themselves by careful evaluation of their own symptoms and respiratory function. Patients attending two lessons with helpful training tools can increase significantly asthma knowledge, treatment compliance and patient selfmanagement ${ }^{17}$. In the present study, economic status played a significant role in achieving the compliance to the aerosol therapy in asthma. It was observed that there were higher default rates among lower socio-economic class patients. Thus the relationship between hospital characteristics and the economic status of the patient is important in view of management of a case of bronchial asthma as medications has to be taken on a regular basis for long term. Length of stay (LOS), and costs per discharge were studied from the Taiwan National Health Insurance Research Database covering the period from 1997 to $2001^{18}$. Study subjects were identified from the database by principal diagnosis of asthma or asthmatic bronchitis, with a total of 139,630 cases being included in the study. Multiple-regression analyses were performed to explore the relationship between LOS, costs per discharge and hospital characteristics, adjusting for age, gender, and discharge status of patients, as well as complications or co morbidities. The regression analyses showed that, compared with district hospitals, medical centers and regional hospitals have longer and more statistically significant LOS, as well as higher costs. Hospitals operating on a for-profit basis have shorter LOS and lower costs than public and not-for-profit hospitals. This study shows the existence of wide variations in LOS and costs per discharge for asthma hospitalizations, between the various types of hospitals.

The main objective of patient education in bronchial asthma is to provide the patient and the patient's family 
with suitable information and training so that the patient can keep well and adjust according to planned medications. The factors involved in non-compliance in the present study are multi-factorial. A total of 246 patients $(61.5 \%)$ defaulted to the aerosol therapy; the default rate was lower among female patients $(38.7 \%)$ as compared to the male patients $(59 \%)$. The most common reasons for the higher non-compliance rates were side effects to the medications (18\%), higher cost of the therapy $(10 \%)$, feeling of well being on therapy $(8 \%)$ and negligence on the part of the patients (7\%). Other causes for non-compliance for therapy are drug factors, which include difficulties with inhaler devices, awkward regimes (e.g., four times daily or multiple drugs), dislike for medication and distant pharmacies. Non-Drug factors include fears about side effects $(18 \%)$, anger about condition or its treatment $(3 \%)$, forgetfulness or complacency $(5 \%)$ and attitudes toward ill health $(5 \%)$.

Adherent patients had greater understanding about their illness and the options for managing the illness. They also had greater confidence that current management would keep their illness under control. However, management of illness was a mystery for patients with suboptimal adherence, and they had greater faith in the safety of natural remedies. Dowell and Hudson ${ }^{19}$ concluded that accepting the recommended treatment, especially long-term treatment perceived as powerful, requires an acceptance of the illness. Recently, a study by Johnson et al $^{20}$ observed suboptimal adherence for inhalation therapy to be $63 \%$ in patients with chronic obstructive pulmonary disease (COPD). Adherent patients had greater understanding about their illness and options for managing the illness. They also had greater confidence that current management would keep their illness under control. Satisfaction with and faith in the treating physicians were found to be low among the less adherent group compared to highly adherent group. Less adherence patients believed that their doctors had limited management options to offer them ${ }^{17}$.

Differences in both intentional and unintentional health behaviors were observed between the two groups by Johnson et $\mathrm{al}^{20}$. Adherent patients were less likely to be confused about their medications, which might have been result of their greater medication knowledge. Less adherent patients were more likely to vary their recommended management to suit their life style or based on how they felt. "Routinization" i.e., the ability to fit to a medication regimen to one's daily routine, has been recognized as a major determinant of improved adherence ${ }^{20}$. Associated comorbid condition is also one of the important factors responsible for the noncompliance in therapy. Depression is known to be a risk factor for the nonadherene ${ }^{21}$. In the present study any specific questions about depression in the questionnaire were avoided due to the sensitivity of the topic and concerns about patient non response. Patient's acceptance of the disease process and recommended treatment, knowledge about and faith in the treatment, effective patient-clinician interaction, and routinization of drug therapy are critical for optional medication adherence in bronchial asthma patients ${ }^{22}$. In early consultation for example, different inhaler devices should be demonstrated, and patients should take part in a decision as to which is most suitable for them.

In the past variety of interventions to improve the patient adherence, ranging from simple adjustments $\mathrm{I}$ the medication regimen to complex multidisciplinary interventions that address health care barriers and communications between patients and care givers were tested I different studies. Unfortunately, the overall quality of published studies varies widely in terms of study design and outcome measures ${ }^{23}$. Recently, Kripalani et $\mathrm{al}^{24}$ published a systematic review after analyzing 38 studies, and it was observed that several types of interventions (including informational, behavioral, and combined informational, behavioral, and/or social investigations) are effective in improving medications adherence. However, only a few of these interventions significantly lead to an improvement in clinical outcome ${ }^{25}$. It is frustrating and goes against our intuition and training that spending time and effort, interacting with patients, and building rapport does not seem to be very effective in improving compliance $^{26}$. It is better to design programs that are more convenient and comfortable. Patients take drugs only if they agree that these agents are more beneficial than disruptive ${ }^{27}$.

\section{References}

[1] Cochrane GM. Compliance and outcomes in patients with asthma. Drugs 1996; 52:S12-S19.

[2] Deenen T, Klip EC. Coping with asthma. Respir Med 1993; 87:S67-S70.

[3] Barnes P, Jonsson B, Klim JB. The costs of asthma. Eur Respir J 1996: 9:636-642.

[4] Global Initiative for Asthma (GINA). Global strategy for Asthma Management and Prevention. Bethesda, National Institute of Health, 2011 (Revised 2011). Downloaded from http://www.ginasthma.com (Accessed on December 20, 2012).

[5] Prasad B.G.; Changes proposed in the social classification of Indian family's. J Indian Med Assoc 1970: 55:198-199.

[6] Pinto Pereira LM, Clement Y, Da Silva CK, McIntosh D, Simeon DT. Understanding and use of inhaler medication by asthmatics in specialty care in Trinidad. Chest 2002; 121: $1833-1840$.

[7] Rand CS, Wise RA. Measuring adherence to asthma medication regimens. Am J Respir Crit Care Med 1994; 149:69-78.

[8] Stern L, Berman J, Lawry W, et al. Medication compliance and disease exacerbation in patients with asthma. Ann Allergy Asthma Immunol 2006; 97:402- 408.

[9] Osterberg L, Blaschke T. Adherence to medication. N Engl J Med 2005; 353:487- 497. 
[10] Kaisar HB. Compliance and non-compliance in asthma. Allergy Asthma Proc 2007; 28:514 - 516.

[11] Rhodes L, Moorman JE, Redd SC. Sex differences in asthma prevalence and other diseases in eight states. J Asthma 2005; 42:772-782.

[12] Gibson N A, Ferguson AE, Aitchson TC, Patson JY. Compliance with inhaled asthma medication in preschool children Thorax 1995; 50: 1274-9.

[13] Lewis M, Lewis C. Consequences of empowering children to care for themselves. Pediatrician 1990; 17:63-7

[14] Juniper EF. The impact of patient compliance on effective asthma management. Curr Opin Pulmon Med 2003; 9: S8S10.

[15] Williams LK, Joseph CL, Peterson EL, et al. Race-ethnicity, crime, and other factors associated with adherence to inhaled corticosteroids. J Allergy Clin Immunol 2007; 119:168-175.

[16] Lindberg M, Estrom J, Moller M, Ahlner J. Asthma care and factors affecting medication compliance: The patient point of view. Intern J Quality Health Care 2001; 13: 375-383.

[17] Cegala DJ, Marinelli T, Post D. The effects of patient communication skills training on compliance. Arch Fam Med 2000; 9:57-64.

[18] Lin HC, Kao, Wen Hc, Wn CS, Chung CL. Length of stay and costs for asthma patients by hospital characteristics-a five-year population-based analysis. J Asthma 2005; 42: 537-542.
[19] Dowell J, Hudson H. A qualitative study of medicationtaking behaviour in primary care. Fam Pract 1997; 14:369375 .

[20] Johnson G, David CMK, Rambha T, Kay S. Factors associated with medication non-adherence in patients with COPD. Chest 2005; 128: $3198-3204$.

[21] Dimatteo MR, Lepper HS, Croghan TW. Depression is a risk factor for noncompliance with medical treatment: Meta analysis of the effects of anxiety and depression on patient adherence. Arch Intern Med 2000; 160: 2101-2107.

[22] Ryan GW, Wagne GJ. Pill taking "routinization": a critical factor to understanding episodic medication adherence. AIDS Care 2003: 15: 795-806.

[23] Gillinssen A. Patient's adherence in asthma. J Physio Phamacol 2007;58(Suppl 5)205-222.

[24] Kripalani S, Yao X, Haynes B. Interventions to evaluate medications adherence in chronic medical conditions. Arch Intern Med 2007;167:540-550.

[25] Bender BG, and Bender SE. Patient-identified barriers to asthma treatment adherence: Response to interviews, focus groups, and questionnaires. Immunol Allergy Clin North Am 2005; 25:107-130.

[26] Brown MD, Reeves MJ, Meyerson K, et al. Randomized trial of a comprehensive asthma education program after an emergency department visit. Ann Allergy Asthma Immunol 2006; 97:44-51.

[27] Gillissen A, Buschi K, Juergens U. Adherence to therapy in bronchial asthma. Dtsch Med Wochenschr 2007;132(23):1281-1286 (English Abstract). 